\title{
Gender effects on phonological processing and reading development in Northern Sotho children learning to read in English: A case study of Grade 3 learners
}

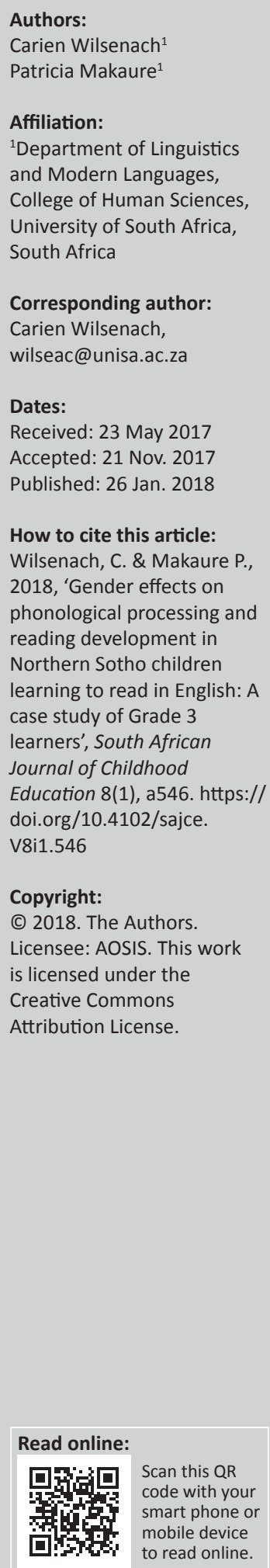

Gender differences in reading development are a global phenomenon, with girls typically performing better than boys. Some studies have reported gender differences favouring girls in reading comprehension in South Africa, but little systematic evidence exists about gender differences in the cognitive-linguistic abilities that underlie reading development. This study investigated the effect of gender on phonological processing and reading development in Northern Sotho-English bilingual children. Grade 3 learners who received their literacy instruction in English were tested on various phonological processing and reading measures. Phonological awareness was assessed using phoneme isolation and elision tasks. Phonological working memory was assessed using memory for digits and non-word repetition tests while rapid automatised naming was tested using rapid letter, rapid digit, rapid object and rapid colour naming tasks. Reading achievement was assessed with various word reading tasks and with a fluent reading task. A multivariate analysis of variance revealed that gender had a significant effect on the phonological processing and reading abilities of Northern SothoEnglish bilingual children. Girls performed significantly better than boys on all the reading measures, as well as on some aspects of phonological processing. The findings provide behavioural evidence in support of biological theories of gender differences, in that girls seemed to have developed some of the cognitive-linguistic skills associated with reading before boys. The girls also coped better with tasks that required increased cognitive processing. This study suggests that sex differences in reading development cannot be ignored in South Africa and need to be addressed in future curriculum development.

\section{Introduction}

Gender differences in reading attainment is a well-documented phenomenon, with several recent reports indicating that boys' underachievement in reading, relative to girls, is an issue of concern (Krizman, Skoe \& Kraus 2011:595; Limbrick, Wheldall \& Madelaine 2011:3; Martino \& Kehler 2007:407; Rutter et al. 2004:1; USAID 2013:1). Some scholars believe that gender differences in reading achievement are exaggerated and misrepresented (Husain \& Millimet 2009:38; White 2007:570), or that they mainly occur in low socioeconomic groups (Commonwealth of Australia 2002:265; Entwisle, Alexander \& Olson 2007:129). However, evidence from international reports, such as the 2001, 2006 and 2011 PIRLS (Progress in International Reading and Literacy Study) and the 2003, 2006 and 2012 PISA (Program for International Student Assessment) studies, overwhelmingly point to a female advantage in various aspects of reading ability, particularly in young and adolescent learners (Marks 2008; Mullis et al. 2003, 2007, 2012; OECD 2004, 2007, 2013). Gender differences are typically reported in reading comprehension (Mullis et al. 2003, 2007), reading motivation, attitude and self-efficacy (Logan \& Johnston 2010:176; McGeown et al. 2012:333). Furthermore, boys often have weaker linguistic skills (associated with reading) than girls (Burman, Bitan \& Booth 2008:1349). It seems fair to conclude that a gender gap in reading achievement exists globally, regardless of learning environment or socio-economic status - a situation which has been referred to as the 'boy crisis' and which has been debated extensively (Fairlie 2016:59; Loveless 2015:9).

In South Africa, the evidence reverberates the global trend, with girls performing better in reading comprehension than boys in the PIRLS and other studies (Howie et al. 2011:28; Van Staden \& Howie 2012:95; Zuze \& Reddy 2014:105). The majority of South African learners have to start using English as the language of learning and teaching (LoLT) in Grade 4 and thus have to acquire adequate cognitive-linguistic skills in English in order to attain academic success. As far as we

Note: The research of this article is based on a master's thesis previously published by the author. 
know, no systematic research has compared the development of specific cognitive-linguistic skills in Northern SothoEnglish bilingual boys and girls, and thus the role that these skills play in the reading development of boys in this population is unclear. This study compares the development of one range of English cognitive-linguistic skills, namely phonological processing skills, in Northern Sotho-English bilingual boys and girls, with the aim of better understanding the role that these skills might play in the underachievement of boys in the South African educational system.

\section{Literature review Explaining gender differences in reading development}

Multiple explanations have been offered for gender differences in reading (Gunzelmann \& Connell 2006:2; Loveless 2015:10). Three prominent explanations are (1) biological, where the assumption is that differential brain structures and hemispheric activation patterns cause the sexes to be hardwired differently for reading, with girls developing the cognitive skills associated with reading before boys, (2) schooling, where the assumption is that practices within schools favour girls and 'girly' behaviour, and that boys are, as a result, lagging behind on several behavioural, social and academic measures and (3) cultural influences, where the assumption is that 'literacy' is defined as a feminine characteristic - propagated by an overrepresentation of female teachers - and that modern culture steers boys towards activities such as sport and computers (Loveless 2015:10). It is important to note here that the terms 'sex' and 'gender' are often used interchangeably when highlighting gender differences in reading ability, but these terms are in fact not interchangeable (McGeown et al. 2012:328). 'Sex' refers to the biological differences that exist between male and female anatomy (including brain structure), while 'gender' refers more to an individual's masculine or feminine identity (i.e. the extent to which someone displays traits commonly associated with being male or female). The possibility of differences in reading ability between boys and girls being the result of gender identity, rather than biological differences, should thus always be kept in mind. Even so, as the current study focuses on the development of phonological processing skills, a set of skills which depends on the development of the broader auditory processing system, the focus here is on cognitive-biological differences.

Regarding the biological make-up of boys and girls, it has been argued that 'differential brain wiring' and 'maturation rates' are important underlying cognitive-biological factors that may explain differences in reading performance (Watson, Kehler \& Martino 2010:357; White 2007:3). The brain wiring view states that girls have an advantage in language-related tasks, including reading, as a result of their relative left hemisphere strength (Alloway et al. 2002:54), and because of their greater bilateral brain activation during language processing tasks - specifically of the left fusiform gyrus, inferior frontal gyrus and superior temporal gyrus (Burman et al. 2008:1358; Plante et al. 2006:1211). The left brain strength of girls has been offered as one explanation for their enhanced language skills, while the right hemispheric strength of boys explains their advantage in visual-spatial and visual motor skills, which leads to an advantage in subjects such as science, mathematics and geography (Gunzelmann \& Connell 2006:6; Gurian \& Stevens 2012:2). Another relevant biological difference between boys and girls relate to the corpus callosum (a bundle of tissues connecting the hemispheres), which facilitates communication (i.e. the transmission of information) between the left and the right hemispheres. Girls are estimated to have a bigger corpus callosum than boys - on average 25\% larger by adolescence (Gurian \& Stevens 2012:2) - which enables them to integrate auditory and visual information from the two hemispheres more effectively (Hlabangwane 2002:27). This could mean that girls are better equipped to cope with the demands of reading instruction in the early stages of schooling, when a child is required to integrate auditory and visual information (Ziegler \& Goswami 2005:3). The maturational rate view basically states that girls mature faster than boys cognitively (Klinger, Shulha \& Wade-Woolley 2010:4). The assumption here is that girls' earlier physical maturity leads to earlier maturation of the biomechanical skills (such as fine motor skills) that are needed for reading development. In contrast, boys' fine motor skills mature later, suggesting that they might struggle more to master the biomechanics of reading (Alloway et al. 2002:55; Chuy \& Nitulescu 2009:5). A related theory suggests that gender differences in reading result from differences in auditory processing capabilities. Several scholars have suggested that auditory processing skills develop earlier (Chuy \& Nitulescu 2009:5; Gunzelmann \& Connell 2006:5), and are more enhanced (Burman et al. 2008; Krizman et al. 2011; Limbrick et al. 2011:2; Rowe, Pollard \& Rowe 2005:16; Rowe \& Rowe 2006) in girls than in boys. The fact that the left hemisphere, which is responsible for auditory processing and verbal expression, develops earlier in girls than in boys means that girls are likely to process information more quickly than boys, and they often have better auditory processing capacities. As a result, girls typically acquire vocabulary faster and begin talking earlier, an advantage that persists through the early school years. The delayed development of the auditory processing system in boys continues up until the age of 10, which means that boys' brains essentially process less auditory information during the first decade of their lives (Rowe, Rowe \& Pollard 2004:23). This delay often manifests in boys who appear to 'not listen', or who have difficulties in following verbal instructions and directions (Rowe et al. 2005:2; Rowe \& Rowe 2006:4). The delayed development of auditory processing mechanisms in boys might affect their processing of sounds, which in turn might affect their ability to acquire the phonological processing skills required for reading. In the following section, the phonological skills associated with reading, as well as previously reported gender differences in these skills, are discussed.

\section{Phonological processing skills and reading}

Phonological processing is an auditory processing skill that represents the processing of phonological aspects of the 
auditory signal (Ellis 2007:6). The development of phonological processing skills is crucial for reading development, regardless of phonological structure (simple or complex), orthography (transparent or opaque) and writing system (alphabetic or non-alphabetic) (Castles \& Coltheart 2004; Goswami 2006; McBride-Chang et al. 2008; Milwidsky 2008; Newmans et al. 2010; Wagner et al. 1997; Wilsenach 2013; Ziegler \& Goswami 2005). Phonological processing skills have traditionally been divided into three key constructs, namely phonological awareness (PA), phonological working memory (PWM) and rapid automatised naming (RAN) (Wagner, Torgesen \& Rashotte 1999). ${ }^{1}$ Strong phonological processing skills, particularly those associated with PA, facilitate the successful acquisition of reading skills, since they enable a learner to analyse, manipulate and discriminate the sounds of a language. This is crucially important when learning to read, as it allows children to associate sounds with graphemes, and facilitates the development of stable phoneme-grapheme correspondences. Poor or underdeveloped PA skills lead to poor decoding skills, which, in turn, affects children's reading fluency.

Phonological awareness encompasses 'phoneme awareness', 'onset-rime awareness' and 'syllable awareness' (Milwidsky 2008:39) all of which underscores the ability to break up words into their constituent sounds. Phoneme awareness allows a child to make connections between individual sounds and letters. For example, the word cat can be split into its phonemic components /c/-/a/-/t/, with the phonemes

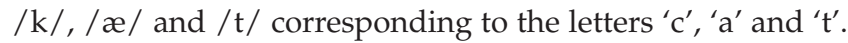
Phoneme awareness develops in response to reading instruction and as such, preliterate children are generally not sensitive to the phonemic constituents of a word (Goswami 2006:4). The development of explicit representations of phonemic structures is a gradual process, which starts around 5-7 years. Onset-rime awareness refers to an individual's sensitivity to the onset and the rime within a word. 'Onset' refers to the initial consonant or consonant cluster in a word, whereas 'rime' is the term used to describe the remaining vowel and consonants (Lane 2007:2). For example, the word cat can be divided into /c/ (onset) and / at/ (rime). Onset-rime awareness helps children to discover word families, which forms the foundation for future spelling strategies (Bear et al. 1996:305) and assists in the automatisation of reading. Syllable awareness is the ability to recognise, segment and blend syllables within a word (Lane 2007:2). For example, the word cowboy can be segmented into two syllabic components /cow/ and /boy/, and the word telephone contains three syllabic units namely /te/-/ le/-/phone/. Apart from segmenting, children should know how to blend separate syllabic units like /im-poss-i-ble/ into

\footnotetext{
1.Scholars like Norton and Wolf (2011:437) and Wolf and Bowers (1999:415) have disputed the inclusion of RAN as a phonological processing skill, and have suggested that although RAN has a phonological component, it represents independent that although RAN has a phonological component, it represents independent
cognitive functions. They argue that RAN taps into a distinct process, namely the cognitive functions. They argue that RAN taps into a distinct process, namely the
ability to rapidly integrate the phonological and visual processes necessary to form ability to rapidly integrate the phonological and visual processes necessary to form
orthographic representations (this naturally also requires sensitivity to orthographic units). In this study, RAN is treated as a phonological process, as the testing units). In this study, RAN is treated as a phonological process, as the testing
instrument employed here included RAN as a component of phonological processing. However, this controversy will be revisited in the discussion.
}

impossible and /o-pe-ra-tion/ into operation. Syllable awareness is generally mastered in kindergarten, and is often considered to be easier than phoneme awareness and onsetrime awareness. The three levels of PA are believed to be differentially related to reading acquisition, with phoneme awareness emerging regularly as the strongest predictor of reading ability (McBride-Chang et al. 2008:186; Newmans et al. 2010:242).

Phonological working memory entails the coding of soundbased representations of spoken (or written) information, which facilitates the temporary storage of such information in working memory (also known as short-term memory) ${ }^{2}$ (Wagner et al. 1997:469). As far as its association with reading goes, the most important component of the working memory system is the 'phonological loop' (Gathercole \& Baddeley 1993:260; Kornacki 2011:1; Miettinen 2012:38). The phonological loop is located in the left temporoparietal region of the brain (Baddeley 2003:831) and consists of a 'short-term phonological store' and an 'articulatory rehearsal component'. The shortterm phonological store is responsible for storing auditory information temporarily. For instance, when auditory information is presented (e.g. when one is given a phone number), speech sounds are analysed and fed into the phonological store, where the memory traces remain for a few seconds before they start fading away (after about $2 \mathrm{~s}$ ) (Kornacki 2011:1). The fading away is counterbalanced by the articulatory loop mechanism, which refreshes the auditory information (Baddeley 2003:833). Thus, the information received in the phonological store is fed into the articulatory rehearsal system, where it is rehearsed sub-vocally (i.e. repeating the phone number in the mind) which reactivates the information in the phonological store (Kornacki 2011:1). PWM skills have been linked to reading achievement (Dahlin 2010:11; Ferreira, Valentin \& Ciasca 2013:7; Kormos \& Sárfár 2008:261). Several explanations exist for this link, the most prominent being that the PWM system maintains phonological information such as words, phrases or sentences for brief periods, which enables a reader to comprehend longer units of text. PWM also plays a critical role when phonemegrapheme correspondences are acquired (Gathercole \& Baddeley 1993:259), as efficient phonological coding of information enables the beginning reader to maintain an accurate representation of the phonemes associated with letters or parts of words (Wagner et al. 1997:369). Once readers become skilled and word recognition becomes automated, less demands are placed on PWM (Gathercole 1998:4).

Rapid automatised naming is the ability to quickly name visually presented familiar symbols. It is divided into two subcategories, namely 'alphanumeric RAN' (i.e. letter

2.The terms PWM and phonological short-term memory (PSTM) are often used interchangeably (Pneuman 2009:83). Attempts have been made to differentiate the tho based on their functions. 'Working memory' typically refers to the active and two based on their functions. Workine and dynamic system that stores information, while also engaging in other cognitively demanding activities (Ellis 2007:46), while 'short-term memory' refers to the more passive storing of material over short periods of time, in situations that do no impose other competing cognitive demands (Miettinen 2012:33). This study does not aim to determine the differences that might exist between the two, and thus
the term PWM is used to refer to the capacity that is often associated with PSTM. 
naming and digit naming) and 'non-alphanumeric RAN' (i.e. object naming and colour naming) (Georgiou et al. 2013:218). The standard format of RAN tasks entails laying out a series of letters, digits, pictures of common objects or colour samples in rows and requesting an individual to name each stimulus in order, from left to right and from top to bottom, as quickly as he or she can (Stringer, Toplack \& Stanovich 2004:892). The metric for RAN tasks is the 'naming speed', measured as the time it takes an individual to name all the stimuli in a series. Researchers in favour of including RAN as a construct within the broader concept of phonological processing believe that RAN tasks involve the rapid transfer of visually presented symbols to phonological codes, which have to be retrieved from the long-term memory store (Wagner et al. 1997:75). A deficit in RAN skills, often referred to as a 'naming speed deficit' (Norton \& Wolf 2011:434), therefore, could represent a difficulty in efficiently and automatically retrieving stored phonological representations, which, in turn, could negatively affect reading speed and reading automaticity. Norton and Wolf (2011:430) argue that RAN constitutes 'a microcosm or mini-circuit of the laterdeveloping reading circuitry', as both systems involve closely related cognitive processes, including (1) attending to stimuli, (2) detecting and discriminating visual features and identifying letters or letter patterns, (3) integrating visual information with stored orthographic and phonological representations, (4) accessing and retrieving phonological codes and (5) organising articulatory output (Araújo et al. 2015:1-2). The development of RAN depends on the veracity of various circuits in the left hemisphere, including the left mid-fusiform area (Lervåg \& Hulme 2009:1046), the left inferior frontal gyrus, left posterior middle frontal gyrus and bilateral inferior occipital areas (Norton \& Wolf 2011:443). Existing evidence which suggests that the development of non-alphanumeric naming may diverge from alphanumeric naming, and that different cognitive processes might be involved in these subtasks (Donker et al. 2016:80).

\section{The development of phonological processing skills in boys and in girls}

In behavioural studies, researchers have consistently found that girls have an overall advantage on phonological tasks, both in natural phonological abilities such as speech production and phonological coding and in PA (which depends more on meta-linguistic abilities and instruction) (Chipere 2014:277). Burman et al. (2008:1352) reported that girls (aged 9-15 years) performed significantly better than boys on rapid naming, and also obtained higher scores on PA. Sex differences in PA favouring girls have also been reported by Lundberg, Larsman and Strid (2010) and by Below et al. (2010). In particular, girls seem to cope better with the demands of phonemic awareness tasks, as measured by intermediary and final phoneme detection tasks (Moura, Mezzomo \& Cielo 2009:53) and phoneme segmentation tasks (Chipere 2014:284). Brain imaging studies indicate that the brain hemispheres of males and females respond differently during phonological processing tasks. The processing of phonological information seems to be lateralised to the left inferior frontal regions in males, while females show more bilateral activation patterns during phonological processing tasks and devote greater right hemispheric resources to these tasks (Burman et al. 2008:1357; Shaywitz et al. 1995:609).

Some scholars have found differences in working memory, suggesting that girls perform better on verbal memory tasks such as digit and object recall, while boys have better abstract visual memory and outperform girls on spatial memory tasks (Wei, Wang \& Wang 2012). There is also evidence to suggest that boys and girls solve problems using different strategies in working memory, depending on the relative strengths of their visuospatial working memory and verbal working memory. Despite some evidence that gender differences exist in working memory, there is also evidence against this position. In studies where no explicit gender differences were observed in verbal working memory, researchers nevertheless found differences in neurological functioning during memory tasks, suggesting that differences become invisible on the surface owing to the sexes using unique cognitive strategies (Lejbak, Crossley \& Vrbancic 2011; Speck et al. 2000). Speck et al. (2000) reported that males used more right hemispheric regions during a verbal memory task, while females used more areas in the left hemisphere.

Following the discussion above, the aim of this study is to contribute to the debate surrounding the development of phonological processing and reading skills in boys and girls. In particular, we hope to determine whether phonological processing skills develop differently in Northern SothoEnglish bilingual boys and girls before the age of 10 years, and whether these skills correlate with reading abilities in a similar manner in the sexes.

\section{Research questions and hypotheses}

The following research questions were addressed in this study:

1. Does gender affect phonological processing abilities and reading development in Northern Sotho-English bilingual children?

2. If so, which aspects of phonological processing and reading are affected by gender?

Given the evidence discussed above, it is hypothesised that the girls in this study will have better reading skills than the boys. It is further anticipated that the boys, who were aged around 9 years, might lag behind on some aspects of phonological processing.

\section{Research methodology and design Participants and research setting}

The current study was conducted in a primary school located in a high-poverty suburb of Tshwane (one of the capital regions of South Africa). The school follows a 'straight for English' language policy, with English being the LoLT from Grade 1. Learners attending the school are from low-income households, as evidenced by the fact that the school is 
classified as a Quintile 2 school and has a feeding scheme. ${ }^{3}$ All the participants included in this study spoke Northern Sotho as home language. ${ }^{4}$ Using a purposive and convenience sampling technique, 60 Grade 3 learners were initially selected and assessed on phonological processing and reading abilities. ${ }^{5}$ However, only 53 participants' data were included in the final analysis, as 7 learners were excluded after they were identified as extreme outliers (using box plots in SPSS) on one or more of the assessments. The final sample consisted of 30 girls (mean age 8.8; SD 0.59) and 23 boys (mean age 8.9; SD 0.71). An independent samples t-test confirmed that there was no significant age difference between the girls and boys $(t=-0.83 ; p=0.532)$.

The learners participated on a voluntary basis after their parents signed an informed consent form. Ethical clearance for the research project was obtained from the Department of Basic Education as well as from the University of South Africa. Learners' identities were kept confidential, and the data were not disclosed to any third party. Any assessment task that proved too difficult for a particular learner was discontinued, in order to minimise psychological stress.

\section{Research design, research materials and data processing}

This study utilised a cross-sectional research design, and entailed an ex post facto comparison of two groups (boys vs girls), with a correlational component. The participants were assessed individually at their school in a quiet room. The data collection was completed over a 5-week period in the second term of the school year. Phonological processing was assessed with the Comprehensive Test of Phonological Processing (CTOPP) (Wagner et al. 1999), word reading was assessed with the Diagnostic Test of Word Reading Processes (FRLL, Institute of Education 2012:6) and fluent reading was assessed using a grade-appropriate reader.

The CTOPP consists of 11 sub-tests, including elision, blending words, phoneme isolation, memory for digits, nonword repetition (NWR), rapid digit naming, rapid letter naming, rapid colour naming, rapid object naming, blending non-words and segmenting non-words. Because of time constraints, only eight tests were utilised here. The CTOPP manual was adhered to meticulously, to ensure that task presentation, feedback to participants, scoring and task conclusion happened in a consistent manner. Raw scores were recorded on the day of testing and were later converted to standard scores (SS) using age norms.

3.In order to determine the allocation of financial resources, South African public schools are categorised into five groups (quintiles). Quintile 1 schools are the 'poorest', while quintile 5 schools are the 'least poor'. The poverty of the community surrounding the school and various infrastructural factors determine the ranking of a school.

4.In South Africa, the term 'home language speaker' is roughly equivalent to the term 'first language speaker'.

5.The rationale for including Grade 3 learners was that the researchers wanted to test reading fluency in both Northern Sotho and English, which is often not possible before Grade 3 in this kind of research setting.
Phonological awareness was measured with the phoneme isolation and the elision sub-tests. The CTOPP also includes blending and segmentation, but these skills were not assessed owing to time constraints (a similar battery of tests were conducted in Northern Sotho, and to keep the time that learners were out of the classroom acceptable, only the isolation and elision sub-tests were used). It was also deemed sensible to include one simple PA task and one complex PA task; hence, the inclusion of the isolation (simple) and elision (more complex) tasks. Phoneme isolation assesses an individual's ability to identify target sounds within words (Wagner et al. 1999:7). The task consisted of 32 items (4 practice and 28 test items). The first 16 items were threesound words, and learners had to identify the first, middle or last sound. For example, the researcher would say 'The word man has three sounds $/ \mathrm{m} /-/ \mathrm{a} /-/ \mathrm{n} /$. What is the first sound in the word man?' The next 16 items were words with more than three sounds and the learners had to identify the second, third or fourth sound. The most difficult items required the learners to identify a sound in a word that had more letters than sounds, for example, 'What is the third sound in the word laughed?' Such items are difficult because the answer cannot be determined using a spelling strategy (i.e. simply naming the sound of the third letter in the word). The elision task measures an individual's ability to produce a word after being instructed to leave out a designated sound or syllable from the beginning, middle or end of the word (Wagner et al. 1999:6). For the syllable deletion part, learners were asked to say a word, and then asked to say the word again after dropping one of the compound syllables. For example, the researcher prompted the participant to say the word toothbrush and then asked the participant to repeat the (remaining) word after deleting a target syllable (Now say toothbrush without saying tooth). For the phoneme deletion part, the learners were required to say a word (Say cup) and then had to say the word after removing a target phoneme (Now say cup without saying / k/). The elision task consisted of 34 items. As the CTOPP treats syllable and phoneme elision as a composite skill, the SS reflects a learners' performance on both aspects of the sub-test.

Phonological working memory was assessed with the digit span and NWR sub-tests. Digit span measures the extent to which an individual can repeat a series of digits ranging in length from two to eight digits (Wagner et al. 1999:7). The learners listened to a recording of numbers (provided as part of the CTOPP test kit) and were asked to repeat the numbers in the correct order. For example, learners had to repeat the digits (53) or (971) in the order in which they were presented. The digit span task consisted of 4 practice and 24 test items. NWR tasks measure an individual's ability to repeat nonwords that vary in length and complexity (Wagner et al. 1999:7). The learners listened to a digital recording of nonwords (provided as part of the CTOPP test kit) and had to repeat the non-words as they heard them. For example, learners had to repeat out loud English made-up words (i.e. non-existing but phonotactically possible words) such as / ral/ and /ballop/. The NWR task consisted of 3 practice and 27 test items. 
Rapid automatised naming was assessed with the rapid letter, rapid digit, rapid object and rapid colour naming subtests. The rapid naming tasks measure the speed with which an individual can name digits, letters, objects and colours (Wagner et al. 1999:7-8). The CTOPP RAN tasks all contain 36 items arranged on separate A4 pages. Each A4 page consists of four rows and nine columns of six randomly arranged numbers (i.e. 2, 3, 4, 5, 7 and 8), or letters (i.e. a, c, k, $\mathrm{n}, \mathrm{s}, \mathrm{t}$ ) or objects (i.e. a pencil, a star, a fish, a chair, a boat and a key) or colours (i.e. blue, red, green, black, yellow and green colour labels). Each RAN task was preceded by six practice items, which were on a separate A4 page. The tasks were presented one after the other, and learners were instructed to name the presented digits, letters, objects and colours as quickly as possible, from left to right until all the items were named. A stopwatch was used to time each participant's response time - the time trial was started as soon as the participant started naming the relevant items. Timing was stopped as soon as the participant finished naming the last item.

Word reading ability in English was tested with the Diagnostic Test of Word Reading Processes (FRLL, Institute of Education 2012:6). This standardised test consists of three sub-tests (non-word reading, exception word reading and regular word reading; each containing 30 items). English fluent reading was assessed with a 1-min test. Raw scores for English fluent reading were calculated by counting the number of words that a child read aloud in $1 \mathrm{~min}$, and subtracting the number of incorrectly read words from this total. For this task, the learners read aloud from the grade-appropriate reader Sindi Makes Tea for Granny (Kingwill 1986).

\section{Data analysis and statistical procedures}

Using the individual SSs, a mean SS was calculated for each of the phonological processing measures in both sexes. A SS on the Diagnostic Test of Word Reading Processes reflects composite score obtained on all three sub-tests (regular word reading, exception word reading and non-word reading), and since we were interested in comparing the performance of boys and girls on each of these sub-tests, the mean raw scores obtained on these tests were used in the analysis. Likewise, the mean raw scores obtained for fluent reading were used. To determine gender effects on phonological processing and reading abilities, a multivariate analysis of variance (MANOVA) (GLM option multivariate) was performed. Gender was entered as an independent variable in the model, while phoneme isolation, elision, NWR, digit span, regular word reading, exception word reading, nonword reading and fluent reading were entered as dependent variables. To determine the extent to which the phonological processing skills correlated with reading skills in the gender groups, Pearson correlations were performed. Because of the relatively small sample, no regression analyses were conducted.

\section{Results \\ Main effects and gender differences}

The Generalised Linear Model (GLM) established a significant main effect for Gender (Pillai's Trace $=0.415, F[12,41]=2.42$; $p=0.02$ ). The effect size for gender was large (judged by Cohen's criterion: Partial Eta Squared $=0.42$ ). Following this significant effect, tests of between-subjects effects were conducted, which showed that Gender had a significant effect on elision $(F[1,52]=7.67 ; p=0.008])$, digit $\operatorname{span}(F[1,52]=5.26$; $p=0.026)$, rapid letter naming $(F[1,52]=4.96 ; p=0.030)$, nonword reading $(F[1,52]=6.87 ; p=0.011)$, exceptional word reading $(F[1,52]=4.96 ; p=0.030)$, regular word reading $(F[1,52]=11.2 ; p=0.002)$ and fluent reading $(F[1,52]=7.96$; $p=0.007)$. Pairwise comparisons indicated that girls significantly outperformed boys on the elision, digit span, rapid letter naming, non-word reading, exceptional word reading, regular word reading and fluent reading tasks. The girls also had a notable advantage in rapid digit naming while the mean difference was not significant, it appeared to be marginally significant $(F[1,52]=3.12 ; p=0.073)$. The means, standard deviations and test statistics obtained for all the measures are presented in Table 1.

\section{Correlational analysis}

Pearson correlations were used to test the relationship between PA, PWM, RAN and reading abilities. The $r$ values are presented in Table 2. In the group of girls, elision correlated moderately with non-word reading, strongly with exceptional word reading and regular word reading and moderately with fluent reading. Digit span positively correlated with fluent reading. Rapid letter naming correlated with regular word reading, while rapid object naming correlated with exceptional word reading, regular word reading and fluent reading. There were no

TABLE 1: Means, standard deviations and test statistics obtained for girls and boys on phonological processing and reading measures.

\begin{tabular}{|c|c|c|c|c|c|c|}
\hline \multirow[t]{2}{*}{ Measures } & \multicolumn{2}{|c|}{ Girls $(n=31)$} & \multicolumn{2}{|c|}{ Boys $(n=23)$} & \multirow[t]{2}{*}{$F$} & \multirow[t]{2}{*}{$P$} \\
\hline & Mean & SD & Mean & SD & & \\
\hline \multicolumn{7}{|l|}{ PA } \\
\hline Isolation SS & 7.0 & 2.2 & 6.5 & 3.0 & 0.47 & 0.496 \\
\hline Elision SS & 8.3 & 3.4 & 5.9 & 2.7 & 7.67 & $0.008 \dagger$ \\
\hline \multicolumn{7}{|l|}{ PWM } \\
\hline Digit span SS & 9.5 & 3.2 & 7.6 & 2.6 & 5.26 & $0.026 \dagger$ \\
\hline NWR SS & 10.32 & 2.8 & 10.4 & 2.8 & 0.01 & 0.929 \\
\hline \multicolumn{7}{|l|}{ RAN } \\
\hline RAN letters SS & 7.0 & 3.0 & 5.0 & 3.6 & 4.96 & $0.030 \dagger$ \\
\hline RAN digits SS & 8.6 & 2.4 & 7.4 & 2.7 & 3.12 & 0.073 \\
\hline RAN colours SS & 10.2 & 2.7 & 9.6 & 3.7 & 0.58 & 0.449 \\
\hline RAN objects SS & 10.8 & 2.2 & 10.2 & 2.6 & 0.94 & 0.336 \\
\hline \multicolumn{7}{|l|}{ English reading } \\
\hline $\begin{array}{l}\text { Regular word reading } \\
\text { raw score }\end{array}$ & 15.6 & 6.3 & 9.5 & 6.9 & 11.2 & $0.002 \dagger$ \\
\hline $\begin{array}{l}\text { Exception word reading } \\
\text { raw score }\end{array}$ & 12.7 & 5.04 & 9.2 & 6.5 & 4.96 & $0.030 \dagger$ \\
\hline $\begin{array}{l}\text { Non-word reading } \\
\text { raw score }\end{array}$ & 9.2 & 6.3 & 5.0 & 5.3 & 6.87 & $0.011 \dagger$ \\
\hline Fluent reading raw score & 55.3 & 22.5 & 36.5 & 26.5 & 7.96 & $0.007 \dagger$ \\
\hline
\end{tabular}

$\dagger$, Significant at the 0.05 level.

NWR, non-word repetition; PA, phonological awareness; PWM, phonological working memory; RAN, rapid automatised naming; SD, standard deviation; SS, standard score. 
significant correlations between isolation, NWR and rapid digit naming and any of the reading measures. In the group of boys, both elision and isolation correlated significantly with all four reading measures. Elision and isolation showed moderate correlations with non-word reading and strong associations with exception word reading. Elision was moderately associated with regular word reading and fluent reading. Isolation was strongly associated with regular word reading and fluent reading. Both alphanumeric RAN tasks (digits and letters) correlated significantly with all four reading measures. Likewise, rapid object naming showed moderate to strong associations with all four reading measures. Rapid colour naming correlated with exceptional word reading, regular word reading and fluent reading. There were no significant correlations between digit span and NWR and any of the reading measures.

\section{Discussion}

The academic achievement of boys in South Africa has been a cause of concern over the past decade, with reports indicating that boys are more likely to repeat a grade or drop out of school (Lee, Zuze \& Ross 2005:212; Zuze \& Reddy 2014:105). This study investigated whether Northern SothoEnglish bilingual boys and girls exhibit differences in their English phonological processing skills, which are crucial for the development of reading skills, and whether there are differences in the word and fluent reading abilities of boys and girls. Grade 3 learners, who speak Northern Sotho as home language but who received their literacy instruction in English from Grade 1, were assessed on various phonological processing skills (PA, PWM and RAN), as well as on nonword reading, regular word reading, exception word reading and fluent reading.

The first question which guided this study was: Does gender affect phonological processing abilities and reading development in Northern Sotho-English bilingual children? A multivariate analysis indicated that gender affected learners' performance on various phonological processing and reading tasks, with girls performing significantly better on some of the phonological processing tasks and on all the reading tasks. The observed effect size of gender was large, suggesting that gender is an important construct in the development of phonological processing and reading literacy in this particular population. These findings resonate with previous South African and international studies indicating that girls perform better than boys in reading (Fairlie 2016:62; Howie et al. 2011:28; Krizman et al. 2011:595; Limbrick et al. 2011:3; Martino \& Kehler 2007:407; Mullis et al. 2003, 2007, 2012; Rutter et al. 2004:1, Van Staden \& Howie 2012:95; USAID 2013:2; Zuze \& Reddy 2014:105). The first researcher hypothesis, is thus affirmed. A straightforward interpretation of the data is that the girls in this study were more successful in acquiring key aspects of phonological processing, and that this enhanced their reading development. The implication of the boys' lag in phonological processing abilities thus needs to be deliberated more carefully. If boys are particularly at risk of not acquiring adequate phonological processing skills in the language in which they are instructed - particularly those skills needed to identify and manipulate syllabic and phonemic constituents within words, word decoding is unlikely to become an automatic process. This would result in boys having reading speeds that are too low to facilitate reading comprehension.

To rectify this situation, the foundation phase curriculum ideally needs to guide teachers explicitly to accommodate the needs of boys during the instruction of phonics. To this end, it is helpful to observe previous research on reading instruction and learning environments that favoured boys. Logan and Johnston (2010:176) report that a systematic synthetic phonics approach, compared to an analytic phonics approach, is better suited to boys' learning styles. Their research (also see Johnston, McGeown \& Watson 2012; Johnston \& Watson 2005) showed that boys who were taught via a systematic synthetic phonics method performed as well as girls in word reading, spelling and reading comprehension. According to Logan and Johnston (2010:176), the 'main principle behind synthetic phonics is that letter-sound correspondences and blending skills are taught early on and at a relatively fast pace so that children quickly have a method to read independently'. Learners are instructed at the grapheme-to-phoneme conversion level and are explicitly taught how to sequentially blend letters in a word, which

TABLE 2: Pearson's correlations between phonological and reading measures for girls and boys.

\begin{tabular}{|c|c|c|c|c|c|c|c|c|c|c|c|c|}
\hline СTOPP sub-tests & 1 & 2 & 3 & 4 & 5 & 6 & 7 & 8 & 9 & 10 & 11 & 12 \\
\hline 1 Elision & & $0.76 \$$ & $0.44 \dagger$ & 0.19 & $0.50 \dagger$ & $0.56 \$$ & 0.24 & 0.39 & $0.47 \dagger$ & $0.66 \ddagger$ & $0.58 \ddagger$ & $0.57 \ddagger$ \\
\hline 2 Isolation & 0.35 & & $0.54 \%$ & $0.42 \dagger$ & $0.62 \ddagger$ & $0.48 \dagger$ & 0.28 & $0.47 \dagger$ & $0.42 \dagger$ & $0.64 \dagger$ & $65 \$$ & 0.68 \\
\hline 3 Digit span & 0.25 & 0.26 & & $0.58 \ddagger$ & 0.35 & 0.19 & 0.29 & 0.30 & 0.13 & 0.21 & 0.21 & 0.22 \\
\hline 4 Non-word repetition & $0.46 \dagger$ & 0.14 & $0.45 \dagger$ & & 0.22 & 0.13 & 0.26 & 0.21 & -0.00 & 0.20 & 0.19 & 0.19 \\
\hline 5 Rapid digit naming & 0.19 & $0.42 \dagger$ & 0.14 & 0.19 & & $0.66 \%$ & $0.60 \%$ & $0.68 \%$ & $0.50 \dagger$ & $0.59 \ddagger$ & $0.59 \ddagger$ & $0.57 \neq$ \\
\hline 6 Rapid letter naming & $0.39 \dagger$ & -0.05 & 0.18 & $0.46+$ & 0.17 & & $0.42 \dagger$ & $0.42 \dagger$ & $0.54 \%$ & $0.71 \ddagger$ & $0.67 \$$ & 0.66 \\
\hline 8 Rapid colour naming & -0.05 & -0.15 & 0.07 & -0.09 & 0.33 & 0.13 & 0.43 & & 0.38 & $0.42 \dagger$ & $0.45 \dagger$ & $0.42 \dagger$ \\
\hline 9 Non-word reading & $0.46 \ddagger$ & 0.14 & 0.08 & 0.26 & 0.20 & 0.29 & 0.15 & 0.27 & & $0.62 \ddagger$ & $0.73 \ddagger$ & 0.75 * \\
\hline 10 Exception word reading & $0.66 \ddagger$ & 0.33 & 0.24 & 0.30 & 0.31 & 0.28 & $0.40 \dagger$ & 0.26 & $0.58 *$ & & $0.95 *$ & $0.90 \%$ \\
\hline 11 Regular word reading & $0.71 \ddagger$ & 0.27 & 0.19 & 0.34 & 0.26 & $0.41 \dagger$ & $0.41 \dagger$ & 0.26 & $0.74 \ddagger$ & $0.85 \ddagger$ & & $0.96 \%$ \\
\hline 12 Fluent reading & $0.54 \dagger$ & 0.20 & $0.42 \dagger$ & 0.28 & 0.28 & 0.33 & $0.54 \$$ & 0.29 & $0.55 t$ & $0.84 \dagger$ & $0.77 \ddagger$ & \\
\hline
\end{tabular}

$\dagger$, Correlations significant at the 0.05 level (two tailed); $\$$, correlation significant at the 0.01 level (two tailed).

Correlations for girls are reported below the diagonal and correlations for boys are reported above the diagonal. 
facilitates decoding. Logan and Johnston (2010:177) offer various reasons why a systematic synthetic phonics approach may be better suited to boys' learning styles. Firstly, a systematic method does not rely on preliteracy skills as much as analytic approaches; thus, boys who have lower levels of reading readiness are not further disadvantaged. Secondly, it might be easier for children to remain focused during synthetic phonics instruction; thus, boys who have attention problems (boys are three times as likely as girls to be diagnosed with attention deficit disorders) areaccommodated. Thirdly, children use different cognitive skills during word recognition when they learn through a synthetic phonics method (compared with other approaches), and possibly the cognitive skills underpinning word recognition in synthetic phonics are as well developed in boys as in girls. Fourthly, the integration of phonological and visual information is stimulated early on in synthetic phonics, which may help boys to integrate information received from different pathways - something they don't do as readily as girls. Lastly, a systematic synthetic phonics method teaches children to read using a rule-based phonological approach (rather than focusing on whole-word recognition, guessing words using the context or predicting words based on grammatical knowledge) and it is possible that a single rulebased method is more suited to boys' learning styles at the outset of literacy instruction.

The second research question was: Which aspects of phonological processing and reading are affected by gender? Significant gender effects (favouring girls) were observed for PA (elision), PWM (digit span) and RAN (rapid letter naming). The girls also performed noticeably better in rapid digit naming, with the mean difference being marginally significant. The data reported here suggest that not all aspects of phonological processing are delayed in boys, as no significant gender differences manifested for the constructs isolation, NWR, rapid colour naming or rapid object naming. The girls' better performance in elision is telling, as this was the most taxing of the PA tasks. The elision task required the learners to not only identify phonemes or syllables in various positions within a word but to also delete the identified phoneme or syllable from the word and to retain the remaining constituents of the word in their short-term memory. As such, the elision task taxed the available cognitive processing resources much more than the isolation task. Phoneme isolation requires only positional awareness and places few demands on processing capacity, as individuals can (to a certain extent) complete the task by using a spelling strategy (i.e. naming a phoneme based on the letter that is in the same position in the word). Castles and Coltheart (2004:86) noted that PA is often conceptualised as a unitary construct, but that it entails several different sub-processes, which differ in terms of complexity. Simpler PA processes include identification or categorisation of sounds, whereas more complex PA processes require individuals to break down words into their constituent parts - as in phoneme or syllable segmentation tasks and in phoneme or syllable deletion tasks. Yet another set of (more complex) skills, associated with being able to string isolated sounds together to form words, are required in blending tasks. A lot has been written about whether all of these sub-skills correlate with reading and spelling development. Scholars like Wagner et al. (1997) and Castles and Coltheart (2004) have agreed that these skills are typically highly correlated, but that phonological analysis (including sound categorisation, segmentation and deletion) is more predictive of first grade reading, whereas phonological synthesis (including sound blending) uniquely predicts second grade reading. Thus, identification and segmentation skills are most important early on in reading acquisition, while blending skills are crucial when readers become more fluent. The girls also had an advantage in PWM, and it is tempting to explain their enhanced performance on the elision task as a result of their increased verbal working memory. However, the girls' advantage was limited to the digit span task. While it is not impossible that their enhanced digit span performance reflects a true advantage in PWM, it is important to note that NWR provides a more sensitive measure of online phonological processing than digit span, as individuals performing the task cannot rely on stored lexical representations during recall (Gathercole 1999:415). The sexes were not dissimilar in their ability to repeat non-words, and thus their ability to process, temporarily store and retrieve previously unknown auditory information was the same. In recalling digits, the working memory system will, to some extent, rely on previously stored lexical representations. We can only speculate about why the girls were more successful on this aspect of PWM. It seems unlikely that the phonological loop component of boys' PWM system was impaired, as this should have caused lower scores in NWR too. Possibly, the girls had more stable phonological codes for digits - a reasonable explanation given girls' general linguistic advantage (i.e. one could speculate that the girls acquired the English phonological codes for digits before the boys). This would have increased speed of access and automaticity in task performance in the girls.

With regard to rapid naming, the girls' advantage was limited to alphanumeric (digit and letter) symbols, which supports the idea that alphanumeric and non-alphanumeric RAN rely on different cognitive strengths and can develop at different rates. The phonological codes corresponding to alphanumeric symbols are freely accessible at surface level, and are thus believed to require mainly phonological processing. In contrast, naming symbols that correspond to colours or objects are thought to require additional steps, as an individual has to first perform processing at a conceptual level to determine the semantic content and the name code related to a particular symbol; only after these steps does phonological processing result in the naming of the symbol (Donker et al. 2016:80). The results suggest that the girls' advantage in rapid naming was no longer evident when a task required extra conceptual processing. Thus, their advantage in RAN is limited to the phonological processing domain. A central construct in naming speed is 'automaticity 
in task performance' (Logan, Schatschneider \& Wagner 2012:3), which entails that the more familiar or rehearsed a child is with, for example, letter names, the more automatic the process of naming them becomes and, as a result, the faster they can be named. The girls' performance on the alphanumeric tasks suggests that they were more familiar with letter and digits (and their associated phonological codes) than the boys. Note that the assumption that the phonological codes corresponding to alphanumeric symbols are freely accessible at surface level depends on a presupposition that an individual has fully acquired these codes. This may not be true for the boys. If the boys acquired English letter names and digits later than the girls (or are still in the process of acquiring them), they would have weaker representations of these items in long-term memory. Speed of access to these items would be slower, which could explain their slower and less accurate naming. The learners were similar in their naming of objects and colours. Possibly, owing to the bilingual nature of the sample, the object and colour terms were still being acquired by both sexes, and thus access to these lexical forms would not have been fully automatic in either of the sexes. Another issue is that colour is perceived differently in different cultures, which has an influence on how colour concepts are lexicalised (Stringer et al. 2004:907). In Northern Sotho, speakers do not differentiate between blue and green (the same lexical item is used for both colours). This may have affected the categorisation process when the children acquired the English lexical items corresponding to these colours. In other words, not having conceptualised colours in a 'Western' manner from an early age, the children would have had to more or less re-learn these concepts when they were introduced to them in English, effectively meaning that both sexes could have been disadvantaged in terms of speed of lexical access in the RAN colour task. Finally, RAN is said to measure phonological processing speed combined with fast cross-modal matching of visual symbols and phonological codes. This means that many different cognitive skills are involved in RAN, including general processing speed and capacity (Georgiou et al. 2013), as well as attention focusing; visual, lexical and temporal processing; and word recognition (Norton \& Wolf 2011; Wolf \& Bowers 1999). Taken together, the results from the PA and RAN tasks do seem to indicate that the girls had the edge in terms of general processing speed and processing capacity. However, in order to fully explain the RAN results, one would need evidence from behavioural tasks related to all of these cognitive functions, which are beyond the focus of this study.

The correlational patterns are not straightforward to interpret. The only phonological processing skill that correlated significantly with all the reading measures in a consistent manner in both sexes was elision. Elision correlated moderately with non-word reading and fluent reading in both sexes, and strongly with exception word reading in both sexes. Furthermore, elision correlated strongly with regular word reading in the girls and moderately with regular word reading in the boys. Isolation, in contrast, did not correlate with any of the reading measures in the girls but showed significant associations, ranging from moderate (non-word reading) to moderately strong (exception word reading, regular word reading and fluent reading) in the boys. In terms of PWM, only one significant association was found, between digit span and fluent reading in the girls. In terms of RAN, alphanumeric RAN correlated significantly and consistently with reading skills in boys but not so much with reading skills in girls (the only significant association being between rapid letter naming and regular word reading in the girls). Non-alphanumeric RAN showed greater overlap in the sexes, with rapid object naming correlating significantly with all four reading measures in the boys, and with three of the reading measures in the girls (not with non-word reading). The correlations between rapid object naming and the reading measures were, on the whole, stronger in the boys than in the girls, suggesting that automatisation issues were particularly important in the reading of boys. In terms of rapid colour naming, the pattern is again disparate, with RAN colours correlating with three of the reading measures in the boys (not with non-word reading) but with none of the reading measures in the girls. What is clear from the correlational analysis is that elision is a crucial skill in reading attainment, regardless of the reading task at hand or the gender of the reader and that RAN skills, generally speaking, seemed more significant in boys' reading than in girls' reading. It is also interesting that the construct phoneme isolation significantly correlated with all the reading measures in the boys but not with a single reading measure in the girls. This supports the hypothesis that phonological analysis skills, such as phoneme isolation and segmentation, are particularly important in the beginning stages of reading (even though the boys were in Grade 3, they were reading below grade level, as evidenced by their mean score on the fluent reading test). In the girls, who were more advanced in all aspects of reading, phoneme isolation did not correlate with any of the reading measures, suggesting that the girls had most likely surpassed a level where basic isolation and segmentation skills could explain reading.

Overall, the results provide evidence for cognitive-biological theories of gender differences in reading. Most children who participated in this study were below the age of 10 years, and it is possible that some of the boys were still in the process of acquiring the full range of phonological processing skills essential for reading. The girls were significantly better in some (but not all) of the phonological processing skills. It could be that the boys are merely slower in their development, and that they will catch up with the girls, an interpretation in line with the 'maturational rate' view (Alloway et al. 2002:54; Chuy \& Nitulescu 2009:5; Gunzelmann \& Connell 2006:97; Gurian \& Stevens 2012:2; Klinger et al. 2010:4; Limbrick et al. 2011:2). Gender gaps in reading and phonological processing have also been attributed to differential brain functioning in boys and girls. Females exhibit greater bilateral brain activation during language processing tasks and more enhanced activation of specific areas such as the left fusiform gyrus, inferior frontal gyrus and superior temporal gyrus 
(Burman et al. 2008:1358; Plante et al. 2006:1211). Boys utilise mainly their left hemisphere during language processing tasks. This pattern is also evident during phonological processing tasks (Shaywitz et al. 1995:607). It seems feasible that girls' bilateral activation would favour them in tasks that require greater or more complex cognitive processing, such as phoneme and syllable deletion (i.e. elision in this study). RAN, in particular, depends on the veracity of various circuits in the left hemisphere, including the left mid-fusiform area, the left inferior frontal gyrus, left posterior middle frontal gyrus and bilateral inferior occipital areas. The stronger alphanumeric RAN skills of the girls could possibly be a result of enhanced activation of specific areas in the left hemisphere, but this conclusion naturally remains speculative.

This study had some limitations in terms of its design, related to the small sample size and the non-random selection of the participants (all the learners attended the same school). It should also be acknowledged that we did not control for social factors which could have influenced the outcome. For example, it is not impossible that the curriculum in the foundation phase is more girl orientated or that literacy is perceived as a female characteristic in South Africa (typically, foundation phase teachers will be female in South Africa, as they were in this study). As such, it would be presumptuous to generalise the findings to the population at large. Still, we believe that gender differences in reading in South Africa cannot be overlooked or ignored. Zuze and Reddy (2014:100) have indicated that although the role of gender in South African education has been part of the policy discussion, the topic has not been at the forefront in terms of implementation. Timely and well-thought out reading intervention will enhance boys' academic performance in school, which implies that gender differences in early reading attainment need to be taken seriously in future curriculum development in South Africa. Watson et al. (2010:360) claim that making gender issues an integral part of the curriculum may generate opportunities to create learning environments in which both boys and girls are free to interact and where they are equally stimulated to improve their literacy skills.

\section{Conclusion}

The results of this study reveal a significant gender effect favouring Northern Sotho-English bilingual girls in several cognitive-linguistic tasks within the phonological processing spectrum. Girls also performed significantly better than boys in regular word reading, exception word reading, non-word reading and fluent reading (all linguistic and reading skills were assessed in English). The results suggest that sex (i.e. biological) differences are important in explaining differences in reading and phonological processing abilities between boys and girls and provide behavioural evidence in support of biological theories of the gender gap in reading. More boys are at risk of not acquiring the phonological processing skills necessary to acquire basic reading skills and therefore reading intervention targeting boys should specifically focus on the development of phonological processing skills, particularly those that require the manipulation of phonemic or syllabic constituents within words. Based on the boys' performance on the phonological processing tasks, it is suggested here that boys might benefit from a systematic synthetic phonics approach, which may help them to focus attention and which would provide an approach governed by a single rule to word decoding at the outset of reading instruction.

If the prevailing 'boy crisis' is to be addressed successfully, it might be essential for educational and policy implementers to identify common and separate educational needs of boys and girls and to implement a policy framework with positive strategies to address those needs. Apart from identifying specific pedagogical tools that would assist educators in teaching phonics to boys, other general reading and learning strategies that could be considered include the use of boyfriendly reading materials (i.e. materials that are of interest to boys), the adoption of technology-based programmes (Alloway et al. 2002:199; White 2007:556) and the provision of more male role models to positively influence boys' perceptions of reading (Fairlie 2016:88; Martino \& Kehler 2007:422; Watson et al. 2010:358). Gender differences in reading must be approached from an all-inclusive perspective, which takes into account socioeconomic, cultural, biological and psycholinguistic aspects underlying literacy development, as well as appropriate teaching strategies to remedy the situation.

\section{Acknowledgements}

The authors wish to thank the Research Directorate of the University of South Africa for its financial support, which made this study possible.

\section{Competing interests}

The authors declare that they have no financial or personal relationships which may have inappropriately influenced them in writing this article.

\section{Authors' contributions}

Both C.W. and P.M. contributed to the conceptualisation of this study. C.M. conducted the reading assessments and was responsible for the statistical analyses. C.M. also wrote the introduction, the literature review and the discussion sections. P.M.'s MA dissertation served as basis for some sections of the article, most notably the methodology section. P.M. conducted the phonological processing tasks and was responsible for the initial data processing.

\section{References}

Alloway, N., Freebody, P., Gilbert, P. \& Musprett, P., 2002, Boys, literacy and schooling Expanding the repertoires of practice, Commonwealth Department of Education, Science and Training, Canberra, pp. 1-224.

Araújo, S., Reis, A., Petersson, K.M. \& Faísca, L., 2015, 'Rapid automatized naming and reading performance: A meta-analysis', Journal of Educational Psychology 107(3), 868-883. http://dx.doi.org/10.1037/edu0000006

Baddeley, A.D., 2003, 'Working memory: Looking back and looking forward', National Review of Neuroscience 4(10), 829-839. https://doi.org/10.1038/nrn1201 
Bear, D., Invernizzi, M., Templeton, S. \& Johnston, F., 1996, Words their way: Word study for phonics, vocabulary, and spelling instruction, Prentice-Hall, Upper study for phon
Saddle River, NJ.

Below, J.L., Skinner, C.H., Fearrington, J.Y. \& Sorrell, C.A., 2010, 'Gender differences in early literacy: An analysis of kindergarten through fifth-grade DIBELS probes', School Psychology Review 39, 240-257.

Burman, D.D., Bitan, T. \& Booth, J.R., 2008, 'Sex differences in neural processing of language among children', Neuropsychologia 46(5), 1349-1362. https://doi. org/10.1016/j.neuropsychologia.2007.12.021

Castles, A. \& Coltheart, M., 2004, 'Is there a causal link from phonological awareness to success in learning to read?', Cognition 91(1), 77-111. https://doi.org/10.1016/ S0010-0277(03)00164-1

Chipere, N., 2014, 'Sex differences in phonological awareness and reading ability', Language Awareness 23(3), 275-289. https://doi.org/10.1080/09658416.2013.7 74007

Chuy, M. \& Nitulescu, R., 2009, 'PISA: Explaining the gender gap in reading through reading engagement and approaches to learning', British Educational Research Journal 14(2), 1-38.

Commonwealth of Australia, 2002, Boys: Getting it right, Report on the inquiry into the education of boys, house of representatives standing committee on education and training, ACT: The Parliament of the Commonwealth of Australia, Canberra, viewed 01 March 2017, from http://www.aph.gov.au/house/committee/edt/ eofb/index.html

Dahlin, K.I.E., 2010, 'Effects of working memory training on reading in children with special needs', Reading and Writing 12, 1-13.

Donker, M.H., Kroesbergen, E.H., Slot, E.M., Van Viersen, S. \& De Bree, E.H., 2016 , 'Alphanumeric and non-alphanumeric rapid automatized naming in children with reading and/or spelling difficulties and mathematical difficulties', Learning and Individual Differences 47, 80-87. https://doi.org/10.1016/j.lindif.2015.12.011

Ellis, J.A., 2007, 'Memory patterns in children with reading disabilities, with and without auditory processing disorders', Doctoral thesis, University of Florida.

Entwisle, D.R., Alexander, K.L. \& Olson, L.S., 2007, 'Early schooling: The handicap of being poor and male', Sociology of Education 80, 114-138. https://doi.org/ being poor and male', Sociology
$10.1177 / 003804070708000202$

Fairlie, R.W., 2016, 'Do boys and girls use computers differently, and does it contribute to why boys do worse in school than girls?', Journal of Economic Analysis Policy 16(1), 59-96. https://doi.org/10.1515/bejeap-2015-0094

Ferreira, T.L., Valentin, C.M.T. \& Ciasca, S.M., 2013, 'Working memory and reading development', Psychology 4(10), 7-12. https://doi.org/10.4236/psych.2013. $410 \mathrm{A002}$

FRLL, Institute of Education, 2012, Diagnostic test of word reading processes, GL Assessment Limited, London.

Gathercole, S.E., 1998, 'The structure and functioning of the phonological short term memory', Journal of Memory and Language 38, 1-8.

Gathercole, S.E., 1999, 'Cognitive approaches to the development of short term memory', Trends in Cognitive Science 3(11), 410-419. https://doi.org/10.1016/ S1364-6613(99)01388-1

Gathercole, S.E. \& Baddeley, A., 1993, 'Phonological working memory: A critical building block for reading development and vocabulary acquisition?', European Journal of Psychology of Education 8(3), 259-272. https://doi.org/10.1007/ BF03174081

Georgiou, G.K., Parilla, R., Cui, Y. \& Papadopoulos, T.C., 2013, 'Why is rapid automatized naming related to reading?', Journal of Experimental Child Psychology 115(1) 218-225. https://doi.org/10.1016/j.jecp.2012.10.015

Goswami, U., 2006, 'Acquiring language and literacy: Cross-language considerations and phonological awareness', Journal of Experimental Child Psychology 82, 1-21.

Gunzelmann, B. \& Connell, D., 2006, 'The new gender gap: Social, psychological, neuro-biological, and educational perspectives', Educational Horizons $84(2)$, neuro-bio.

Gurian, M. \& Stevens, S., 2012, 'With boys and girls in mind', Educational Leadership $6(3), 21-26$

Hlabangwane, G.T., 2002, 'Central processing disorders: Training and knowledge of urban black mainstream primary school teachers in Soweto', MA thesis, University of Pretoria.

Howie, S., Van Staden, S., Tshele, M., Dowsie, C. \& Zimmerman, L., 2011, South African children's reading literacy achievement: The progress in international reading literacy study, Centre for Evaluation and Assessment, Pretoria.

Husain, M. \& Millimet, D., 2009, 'The mythical “boy crisis"?', Economics of Education Review 29(1), 38-48. https://doi.org/10.1016/j.econedurev.2007.11.002

Johnston, R.S., McGeown, S. \& Watson, J.E., 2012, 'Long-term effects of synthetic versus analytic phonics teaching on the reading and spelling ability of 10 year old
boys and girls', Reading and Writing 25, 1365-1384. https://doi.org/10.1007/ boys and girls', Rec
s11145-011-9323-x

Johnston, R.S. \& Watson, J.E., 2005, 'A seven-year study of the effects of synthetic phonics teaching on reading and spelling attainment', in Insight 17, Scottish Executive Education Department (SEED), Edinburgh, pp. 1-8.

Kingwill, P., 1986, Sindi makes tea for Granny. Based on a story told by S. N. Mhaga Oxford University Press, Oxford.

Klinger, D.A., Shulha, L.A. \& Wade-Woolley, L., 2010, 'Towards an understanding of gender differences in literacy achievement', The Education Alliance 1, 2-14.

Kormos, J. \& Sárfár, A., 2008, 'Phonological short-term memory, working memory and foreign language performance in intensive language learning', Bilingualism Language and Cognition 11(2), 261-271. https://doi.org/10.1017/S136672 8908003416
Kornacki, T., 2011, 'Measuring phonological short-term memory, apart from lexical knowledge', MA thesis, University of Toronto.

Krizman, J., Skoe, E. \& Kraus, N., 2011, 'Sex difference in subcortical auditory functions', Clinical Neurophysiology 123, 590-597. https://doi.org/10.1016/j.clinph.2011. 07.037

Lane, H.B., 2007, 'Phonological awareness: A sound beginning', paper presented at the 2 nd Annual Struggling Reader Conference, Athens, 6-7th September.

Lee, V.E., Zuze, T.L. \& Ross, K.R., 2005, 'School effectiveness in 14 sub-Saharan African countries: Links with 6 th graders' reading achievement', Studies in Educationa Evaluation 31, 207-224. https://doi.org/10.1016/j.stueduc.2005.05.011

Lejbak, L., Crossley, M. \& Vrbancic, M., 2011, 'A male advantage for spatial and object but not verbal working memory using the n-back task', Brain and Cognition 76, but not verbal working memory using the $n$-back task',
191-196. https://doi.org/10.1016/j.bandc.2010.12.002

Lervåg, A. \& Hulme, C., 2009, 'Rapid automatized naming (RAN) taps a mechanism that places constraints on the development of early reading fluency', Psychologica Science 20(8), 1040-1048. https://doi.org/10.1111/j.1467-9280.2009.02405.x

Limbrick, L., Wheldall, K. \& Madelaine, A., 2011, 'Why do more boys than girls have a reading disability? A review of the evidence', Australasian Journal of Special Education 35(1), 1-24. https://doi.org/10.1375/ajse.35.1.1

Logan, J.A.R., Schatschneider, C. \& Wagner, R.K., 2012, 'Rapid serial naming and reading ability: The role of lexical access', Reading and Writing 24(1), 1-25. https://doi.org/10.1007/s11145-009-9199-1

Logan, S. \& Johnston, R., 2010, 'Investigating gender differences in reading', Educational Review 62(2), 175-187. https://doi.org/10.1080/00131911003637006

Loveless, T., 2015, The 2015 Brown Center report on American education: How well are American students learning? With sections on the gender gap in reading, effects of the common core, and student engagement, The Brookings Institution, effects of the comm

Lundberg, I., Larsman, P. \& Strid, A., 2010, 'Development of phonological awareness during the preschool year: The influence of gender and socio-economic status', Reading and Writing 25(2), 305-320. https://doi.org/10.1007/s11145o10-9269-4

Marks, G.M., 2008, 'Accounting for the gender gaps in student performance in reading and mathematics: Evidence from 31 countries', Oxford Review of Education 34(1), 89-109. https://doi.org/10.1080/03054980701565279

Martino, W. \& Kehler, M., 2007, 'Gender-based literacy reform: A question of challenging or recuperating gender binaries', Gender and Education 30(2), 406431. https://doi.org/10.2307/20466644

McBride-Chang, C., Tong, X.L., Shu, H., Wong, A.M.Y., Leung, K.W. \& Tardif, T., 2008, 'Syllable, phoneme, and tone: Psycholinguistic units in early Chinese and English word recognition', Scientific Studies of Reading 12, 171-194. https://doi. org/10.1080/10888430801917290

McGeown, S., Goodwin, H., Henderson, N. \& Wright, P., 2012, 'Gender differences in reading motivation: Does sex or gender identity provide a better account?', Journal of Research in Reading 35(3), 328-336. https://doi. org/10.1111/j.1467-9817.2010.01481.x

Miettinen, H., 2012, 'Phonological working memory and L2 knowledge: Finnish children learning English', MA thesis, University of Jyväskylä.

Milwidsky, C., 2008, 'Working memory and phonological awareness', MA thesis, University of Witwatersrand.

Moura, S.R.S., Mezzomo, C.L. \& Cielo, C.A., 2009, 'Phonemic awareness stimulation and its effects regarding the variable gender', Pró-Fono Revista de Atualização Científica 21(1), 51-56. https://doi.org/10.1590/S0104-56872009000100009

Mullis, I.V.S., Martin, M.O., Gonzalez, E.J. \& Kennedy, A.M., 2003, PIRLS 2001 International report: IEA's study of reading literacy achievement in primary schools, TIMSS \& PIRLS International Study Center, Boston College, Chestnut Hill, MA.

Mullis, I.V.S., Martin, M.O., Kennedy, A.M. \& Foy, P., 2007, IEA's progress in international reading literacy study in primary school in 40 countries, TIMSS \& PIRLS reading literacy study in primary school in 40 countries,
International Study Center, Boston College, Chestnut Hill, MA.

Mullis, I.V.S., Martin, M.O., Foy, P. \& Drucker, K.T., 2012, PIRLS 2011 internationa results in reading, TIMSS \& PIRLS International Study Center, Boston College, Chestnut Hill, MA.

Newmans, E.H., Tardiff, R., Huang, J. \& Shu, H., 2010, 'Phonemes matter: The role of phoneme-level awareness in emergent Chinese readers', Journal of Experimental Psychology 108, 248-259. https://doi.org/10.1016/j.jecp.2010.09.001

Norton, E.S. \& Wolf, M., 2011, 'Rapid automatized naming (RAN) and reading fluency: Implications for understanding and treatment of reading disabilities', Annual Review Psychology 63, 427-452. https://doi.org/10.1146/annurev-psych-120710 100431

OECD, 2004, Learning for tomorrow's world - First results from PISA 2003, OECD Publishing, Paris.

OECD, 2007, PISA 2006: Science competencies for tomorrow's world: Volume 1: Analysis, OECD Publishing, Paris.

OECD, 2013, PISA 2012 results: Ready to learn (volume III): Students' engagement, drive and self-beliefs, OECD Publishing, Paris.

Plante, E., Schmithorst, V.J., Holland, S.K. \& Byars, A.W., 2006, 'Sex differences in the activation of language cortex during childhood', Neuropsychologia 44, 12101221. https://doi.org/10.1016/j.neuropsychologia.2005.08.016

Pneuman, S.M., 2009, Defining the early indicators of dyslexia: Providing the signposts to intervention, Doctoral thesis, University of Bath.

Rowe, K., Pollard, J. \& Rowe, K., 2005, 'Literacy, behaviour and auditory processing: Does teacher professional development make a difference?', viewed 06 March 2014, from http://www.acer.edu.au/research/programs/learningprocess.html 
Rowe, K. \& Rowe, K., 2006, 'Big issues in boys' education: Auditory processing capacity, literacy and behaviour', Australian Council for Educational Research 9 2-10.

Rowe, K., Rowe, K. \& Pollard, J., 2004, 'Literacy, behaviour and auditory processing: Building "fences" at the top of the "cliff" in preference to "ambulance services" at the bottom' in Research Conference 2004 Proceedings, Australian Council for Educational Research, Camberwell, VIC, pp. 34-52.

Rutter, M., Caspi, A., Ferguson, D., Horwood, L.J., Goodman, R., Maughan, B. et al., 2004, 'Sex differences in developmental reading disability', American Medical Association 291(16), 1-6. https://doi.org/10.1001/jama.291.16.2007

Shaywitz, B.A., Shaywitz, S.E., Pugh, K.R., Constable, R.T., Skudlarski, P., Fulbright, R.K. et al., 1995, 'Sex differences in the functional organization of the brain for language', Nature 373, 607-609. https://doi.org/10.1038/373607a0

Speck, O., Ernst, T., Braun, J., Koch, C., Miller, E. \& Chang, L., 2000, ‘Gender differences in the functional organization of the brain for working memory', NeuroReport 11(11), 2581-2585. https://doi.org/10.1097/00001756-200008030-00046

Stringer, R.W., Toplack, M.E. \& Stanovich, K.E., 2004, 'Differential relationships between RAN performance, behaviour ratings, and executive function measures: Searching for a double dissociation', Reading and Writing: An Interdisciplinary Journal 17, 891-914. https://doi.org/10.1007/s11145-004-2770-x

USAID, 2013, Reading skills and gender: An analysis, Education Data for Decision Making, viewed 25 November 2014, from www.eddataglobal.org

Van Staden, S. \& Howie, S., 2012, 'Reading between the lines: Contributing factors that affect Grade 5 student reading performance as measured across South Africa's 11 languages', Educational Research and Evaluation: An International Journal on Theory and Practice 18(1), 85-98. https://doi.org/10.1080/13803611. 2011.641270

Wagner, R.K., Torgesen, J.K. \& Rashotte, C.A., 1999, Comprehensive test of phonological processing, Pearson Assessments, San Antonio, TX.
Wagner, R.K., Torgesen, J.K., Rashotte, C.A., Hecht, S.A., Barker, T.A., Burgess, S.R. et al., 1997, 'Changing relations between PP abilities and word-level reading as children develop from beginning to skilled readers: A 5-year longitudinal study', Developmental Psychology 33, 468-479. https://doi.org/10.1037/0012-1649. Developm
33.3.468

Watson, A., Kehler, M. \& Martino, W., 2010, 'The problem of boys' literacy underachievement: Raising some questions', Journal of Adolescent and Adult Literacy 53(5), 356-361. https://doi.org/10.1598/JAAL.53.5.1

Wei, Z., Wang, X.J. \& Wang, D.H., 2012, 'From distributed resources to limited slots in multiple-item working memory: A spiking network model with normalization', Journal of Neuroscience 32, 11228-11240. https://doi.org/10.1523/JNEUROSCI. 0735-12.2012

White, B., 2007, 'Are girls better readers than boys? Which boys? Which girls?' Canadian Journal of Education 30(2), 554-581. https://doi.org/10.2307/ 20466650

Wilsenach, C., 2013, 'Phonological skills as predictor of reading success: An investigation of emergent bilingual Northern Sotho/English learners', $P$ er Linguam. A Journal of Language Learning 29(2), 17-32. https://doi. org/10.5785/29-2-554

Wolf, M. \& Bowers, P.G., 1999, 'The double-deficit hypothesis for the developmental dyslexias', Journal of Educational Psychology 91(3), 415-438. https://doi. org/10.1037/0022-0663.91.3.415

Ziegler, J.C. \& Goswami, U., 2005, 'Reading acquisition, developmental dyslexia, and skilled reading across languages: A psycholinguistic grain size theory', Psychological Bulletin 131(1), 3-29. https://doi.org/10.1037/0033-2909. 131.1.3

Zuze, T. \& Reddy, V., 2014, 'School resources and the gender reading literacy gap in South African schools', International Journal of Educational Development 36, 100-107. https://doi.org/10.1016/j.ijedudev.2013.10.002 